\title{
Cytokine Response in Pediatric Patients With Pandemic Influenza H1N1 2009 Virus Infection and Pneumonia: Comparison With Pediatric Pneumonia Without H1N1 2009 Infection
}

\begin{abstract}
Yeo Hyang Kim, MD, PhD, ${ }^{1 \star}$ Jung-Eun Kim, $\mathrm{PhD}^{2}{ }^{2}$ and Myung Chul Hyun, $\mathrm{MD}, \mathrm{PhD}^{3}$
Summary. Objectives: We investigated serum cytokine levels in pediatric patients with pandemic influenza H1N1 2009 virus (H1N1) infection-pneumonia and in pediatric patients with pneumonia but without $\mathrm{H} 1 \mathrm{~N} 1$ infection, and examined correlations between cytokine levels and clinical/laboratory findings. Methods: Fifty-seven cases of infection by $\mathrm{H} 1 \mathrm{~N} 1$ were confirmed by RT-PCR and enrolled. Of these 57 cases, 26 had a severe H1N1 infection (group 1), and 31 had a mild H1N1 infection (group 2). Sera from 18 cases with pneumonia without H1N1 infection (group 3) were used as controls. The serum levels of 10 cytokines were determined by multiplex assay. Results: The serum levels of IFN- $\alpha$, IL-6, and IP-10 were significantly higher in H1N1 infected cases than in group 3, and levels of IL-6 and IP-10 were significantly higher in group 1 than in group 2. The level of IL-10 was significantly higher in groups 1 and 3 than in group 2. However, levels of IFN- $\gamma$ and IL-17 were not significantly different between the three groups. IL-1 $\beta$, IL- 4 , and MIP- $1 \alpha$ were not detectable in most patients. IP-10 and IL-6 levels were found to show negative correlations with lymphocyte count and oxygen saturation. Conclusions: We found higher levels of cytokines (IFN- $\alpha$, IL-6, IP-10) of innate immunity than those of acquired immunity in pediatric $\mathrm{H} 1 \mathrm{~N} 1$ infection. Of the cytokines found to be increased in cases with H1N1 infection, IP-10 and IL- 6 were found to be correlated with disease severity (lymphopenia and hypoxia). IP-10 and IL-6 may be important markers in pediatric H1N1 infection. Pediatr Pulmonol. 2011;46:1233-1239. @ 2011 Wiley Periodicals, Inc.
\end{abstract}

Key words: children; influenza A virus; H1N1 subtype; pneumonia; cytokine; immunity; innate.

Funding source: Bisa Research Grant of Keimyung University in 2010.

\section{INTRODUCTION}

Swine-origin H1N1 influenza virus infection was first detected in Mexico during late March/early April in 2009, and subsequently, a pandemic influenza H1N1 2009 virus (H1N1 2009) infection swept many countries. $^{1-3}$

The H1N1 2009 infection presented as a febrile respiratory infection with variable symptoms, ranging from self-limited to severe illness, ${ }^{1-3}$ which could have been associated with host immune response. Recently, $\mathrm{T}$ helper 1 and $\mathrm{T}$ helper 17 hypercytokinemia has been reported in adult H1N1 2009 cases, ${ }^{4}$ and a study of pediatric H1N1 2009 infection found that cytokine expressions were significantly different between H1N1 2009 infection with pneumonia and without pneumonia, and between cases of severe and mild pneumonia with H1N1 2009 infection. ${ }^{5}$ However, the characteristics of cytokine response caused by H1N1 2009 in the pediatric patients are poorly understood, and it has not been established whether cytokine responses in cases of
H1N1 2009 pneumonia differ from those of cases of non-H1N1 2009 pneumonia.

\footnotetext{
${ }^{1}$ Department of Pediatrics, Keimyung University School of Medicine, Daegu, Korea.
}

${ }^{2}$ Department of Molecular Medicine, Cell and Matrix Research Institute, Kyungpook National University School of Medicine, Daegu, Korea.

${ }^{3}$ Department of Pediatrics, Kyungpook National University School of Medicine, Daegu, Korea.

*Correspondence to: Yeo Hyang Kim, MD, PhD, Department of Pediatrics, Keimyung University School of Medicine, 197 Dongsan-dong, Junggu, Daegu 700-712, Korea. E-mail: kimyhped@hanmail.net

Received 19 December 2010; Revised 5 April 2011; Accepted 27 April 2011.

DOI 10.1002/ppul.21496

Published online 27 May 2011 in Wiley Online Library

(wileyonlinelibrary.com). 
In this study, we measured and compared serum levels of several cytokines in pediatric patients with $\mathrm{H} 1 \mathrm{~N} 1$ 2009 infection and mild or severe pneumonia, and compared the cytokine profiles of patients with H1N1 2009 pneumonia with those of patients with non-H1N1 2009 pneumonia. In addition, we investigated correlations between serum cytokine levels and clinical/laboratory findings.

\section{METHODS}

\section{Patients}

Of pediatric patients with H1N1 2009 infection and pneumonia admitted to the pediatric departments of two medical centers from September 2009 to April 2010, 57 were enrolled in this study. Pediatric patients with H1N1 2009 infection were admitted for 24-48 hr from onset of fever and cough. Pneumonia was confirmed clinically (crackle, wheezing, decreased breath sounds, hypoxia, and tachypnea) and radiologically (consolidation, atelectasis, and infiltration). To compare serum cytokines levels, we allocated the 57 H1N1 2009 infected patients into two groups: group 1 (26 subjects) with a rapid respiration rate for age [as described by the tachypnea criteria of the World Health Organization (WHO)], ${ }^{6}$ and group 2 (31 subjects) with an appropriate respiration rate for age. In addition, 18 pediatric patients with pneumonia without H1N1 2009 infection were enrolled as controls (group 3). They also were admitted for 24-48 hr from onset of fever and cough. Study approval was obtained from the Institutional Review Boards at Kyungpook National University School of Medicine and at Keimyung University School of Medicine.

\section{Samples and Laboratory Studies}

To confirm H1N1 2009 infection, nasal or throat swab specimens obtained at admission were tested for the presence of viral RNA using an RT-PCR (real time reverse transcription polymerase chain reaction) assay (TaqMan ${ }^{\circledR}$ influenza A assay sets, Applied Biosystems, Carlsbad, California). To determine the etiology of pneumonia infections, mycoplasma pneumonia enzymelinked immunosorbent assays, urinary streptococcal antigen assays (BinaxNow ${ }^{\circledR}$ streptococcus pneumonia, Inverness Medical, Scarborough, Maine), and blood cultures were performed. In addition, to identify respiratory virus pathogens, RT-PCR was performed on nasal or throat swabs specimens (RV 12 ACE Detection, Seegene, St. Ingbert, Germany). This RT-PCR testing assay was capable of detecting metapneumovirus, adenovirus, corona virus 229E/NL63, parainfluenza virus $1 / 2 / 3$, influenza $\mathrm{A} / \mathrm{B}$ virus, coronavirus $\mathrm{OC} 43 / \mathrm{HKU} 1$, rhinovirus $\mathrm{A} / \mathrm{B}$, and respiratory syncytial virus $\mathrm{A} / \mathrm{B}$.
Serum samples for cytokine analysis were obtained at admission (24-48 hr from onset of fever and cough) and stored at $-70^{\circ} \mathrm{C}$ until assayed. Ten cytokines were assayed in serum (interferon (IFN)- $\alpha$, IFN- $\gamma$, interleukin (IL)-1 $\beta$, IL-4, IL-6, IL-10, IL-17, interferoninducible protein-10 (IP-10), macrophage inflammatory protein (MIP)-1 $\alpha$, and tumor necrosis factor (TNF)- $\alpha$ ) using the multiplex assay with Instrument Luminex ${ }^{\circledR}$ $200^{\mathrm{TM}}$ Total System (Luminex Corporation, Austin, TX).

\section{Statistics}

SPSS version 18.0 was used for the statistical analysis. Comparisons between groups were performed using the non-parametric Mann-Whitney $U$-test. Data was displayed as mean and standard deviation for laboratory parameters (Table 1), and median and interquartile range for data on the immune mediators levels (Figs. 1 and 2). Correlations between cytokine concentrations and clinical or laboratory data were determined by calculating the Spearman correlation coefficient (r). $P$ values of $<0.05$ were considered significant.

\section{RESULTS}

\section{Patients Characteristics}

Patient characteristics are listed in Table 1. Of the subjects, $65 \%$ were male, and $45 \%$ of these male patients were included in group 1. Mean ages were not significantly different in groups 1,2 , and 3 . Group 1 and 2 were more likely to have asthma than group 3 . Initial hypoxia (room air saturation $<92 \%)^{7}$ was demonstrated by $78 \%$ of group 1 and was more common in this group than in group 2 or $3(P=0.000$, $P=0.000)$. Wheezing was present in $39 \%$ of subjects (50\% of group 1, 29\% of group 2, 39\% of group 3).

Patients with H1N1 2009 pneumonia showed lymphopenia and an elevated C-reactive protein (CRP) level, and these were more prominent in group 1 than in group $2(P=0.015, P=0.000)$. All H1N1 2009 pneumonia patients were treated with neuraminidase inhibitors and some patients required anti-inflammatory adjuvant treatments, that is, systemic corticosteroid and/ or intravenous immunoglobulin, because of aggravated respiratory symptoms (dyspnea or hypoxia).

Acute mycoplasma infection was diagnosed in eight cases ( 3 in group 1, 3 in group 2, and 2 in group 3 ). No case was found positive by streptococcal antigen testing and blood culture. RT-PCR was performed to detect concomitant respiratory virus infections in 42 children (19 in group 1, and 23 in group 2), and 23 were found to harbor co-infections (10 in group 1, and 13 in group 2). Three common co-infection viruses were non-H1N1 influenza $\mathrm{A}$, respiratory syncytial virus $\mathrm{A}$ and human 
TABLE 1-Clinical and Laboratory Characteristics of the Patients

\begin{tabular}{lccc}
\hline & Group 1 & Group 2 & Group 3 \\
\hline Number of patients & 26 & 31 & 18 \\
Sex (M:F) & $22: 4$ & $19: 12$ & $8: 10$ \\
Age, median (range) & $7 \mathrm{yr}(3-11 \mathrm{yr})$ & $6 \mathrm{yr}(4 \mathrm{mo}-16 \mathrm{yr})$ & $5 \mathrm{yr}(3-13 \mathrm{yr})$ \\
Underlying disease & 5 Asthma & 4 Asthma & 0 \\
$\mathrm{O}_{2}$ saturation, mean (SD)(\%) & $92.2(2.8)^{*}$ & $96.2(3.3)$ & $96.5(2.0)$ \\
Hypoxia (no) & $20 / 26$ & $5 / 31$ & $1 / 18$ \\
WBC, mean (SD) $\left(/ \mathrm{mm}^{3}\right)$ & $11,680(3,595)^{*}$ & $8,184(3,764)$ & $8,750(3,119)$ \\
Lymphocyte, mean $(\mathrm{SD})\left(/ \mathrm{mm}^{3}\right)$ & $632(359)^{*}$ & $1,713(1,312)^{\dagger}$ & $2,014(1,847)$ \\
CRP, mean (SD)(mg/dl) & $7.1(4.3)^{*}$ & $2.6(2.6)$ & $2.9(3.9)$ \\
Neuraminidase inhibitors $(\mathrm{no})$ & $26 / 26$ & $31 / 31$ & $0 / 18$ \\
Cephalosporin $(\mathrm{no})$ & $26 / 26$ & $21 / 31$ & $8 / 18$ \\
Macrolide (no) & $26 / 26$ & $30 / 31$ & $13 / 18$ \\
Steroid (no) & $6 / 26$ & $4 / 31$ & $2 / 18$ \\
IVIG (no) & $3 / 26$ & $0 / 31$ & $0 / 18$ \\
\hline
\end{tabular}

M, male; F, female; yr, year; mo, month; SD, standard deviation; no, number; WBC, total white blood cell count; CRP, C-reactive protein; IVIG, intravenous immunoglobulin.

${ }^{*} P<0.05$ versus group 2 and group 3 .

${ }^{\dagger} P<0.05$ versus group 3 .

rhinovirus (HRV). Among group 3, respiratory virus RT-PCR was performed in 18 children. Non-H1N1 influenza $\mathrm{A}$, respiratory syncitial virus $\mathrm{A}$ and adenovirus were found in 4, 2, and 1 patients, respectively. Eleven children showed negative respiratory virus RT-PCR result.

\section{Cytokines Profiling}

Serum concentrations of IFN- $\alpha$, IL-6, and IP-10 were higher in group 1 and 2 than in group $3(P<0.05)$ (Fig. 1). Although IFN- $\alpha$ was not different between group 1 and group $2(P=0.422)$, IL-6 and IP-10 were significantly higher in group 1 than in group 2 $(P=0.009, P=0.027$ ) (Fig. 1).

We found significantly different levels of TNF- $\alpha$ and IL-10 between group 1 and group $2(P=0.003$, $P=0.000)$, and between group 2 and group 3 $(P=0.046, P=0.026)$ (Fig. 2). However, the levels of TNF- $\alpha$ and IL-10 were not different between group 1 and group $3(P=0.389, P=0.183)$ (Fig. 2). No significant group differences were found for serum IFN- $\gamma$ and IL-17. Furthermore, the serum levels of IL-1 $\beta$, IL4 , and MIP- $1 \alpha$ were undetectable in most subjects.

IL-6 and IP-10 levels were found to be negatively correlated with lymphocyte count $(\mathrm{r}=-0.317$, $P=0.004 ; \mathrm{r}=-0.332, P=0.002$ ) (Fig. 3 ) and IP-10 level was also found to be negatively correlated with oxygen saturation ( $\mathrm{r}=-0.386, P=0.000)$ (Fig. 4).

\section{DISCUSSION}

We compared serum cytokine levels of H1N1 2009 and non-H1N1 2009 pneumonia patients, and investigated correlations between cytokine levels and clinical/ laboratory findings. Of the 10 cytokines included in this analysis, significantly higher IFN- $\alpha$, IL-6, and IP-10 levels were found in H1N1 2009 pneumonia patients than in non-H1N1 2009 pneumonia patients. Furthermore, significant negative correlations were found between serum IL-6 and IP-10 levels and disease severity (lymphocyte count, oxygen saturation) in H1N1 2009 pneumonia patients. These results suggest that typical innate immunity is more activated by H1N1 2009 than by other viral infections.

In a recent study using an animal model, strong induction of IFN- $\alpha$, IL-4, IL-5, and IL-10 in the lung of mice and markedly higher levels of MCP-1, MIP- $1 \alpha$, IL-6, and IL-18 in the lung of macaques were found in H1N1 2009 infection than in a seasonal H1N1 infection. ${ }^{8}$ One adult study reported higher serum levels of T-helper 17 mediators (IL-6, IL-8, IL-9, IL-17), T-helper 1 mediators (TNF- $\alpha$, IL-15, IL-12p70), and type-II interferon (INF- $\gamma$ ) in H1N1 2009 patients with severe infection. ${ }^{4}$ Others have reported higher serum levels of pro-inflammatory cytokines and chemokines in H1N1 2009 infected patients with acute respiratory distress syndrome than in mild group and control. ${ }^{9,10}$ Furthermore, these two previous studies demonstrated that $\mathrm{PaO}_{2}$ levels and $\mathrm{PaO}_{2}: \mathrm{FiO}_{2}$ ratios were negatively correlated with serum IL- 6 and IL- 8 levels. ${ }^{4,10}$ The first autopsy case infected by high copy number of H1N1 2009 showed elevation of IL-2R, IL-6, IL-8, IL-10, IP10 , and IFN- $\alpha$ in the serum and lung tissue, and diffuse alveolar damage in microscopic examination. ${ }^{11}$ These results in this autopsy case ${ }^{11}$ and previous reports $4,9,10$ could support high cytokinemia of IL-6 and IP-10 that was showed in group 1 than in group 2 and 3 in the present study. More hypoxic patients were enrolled in 

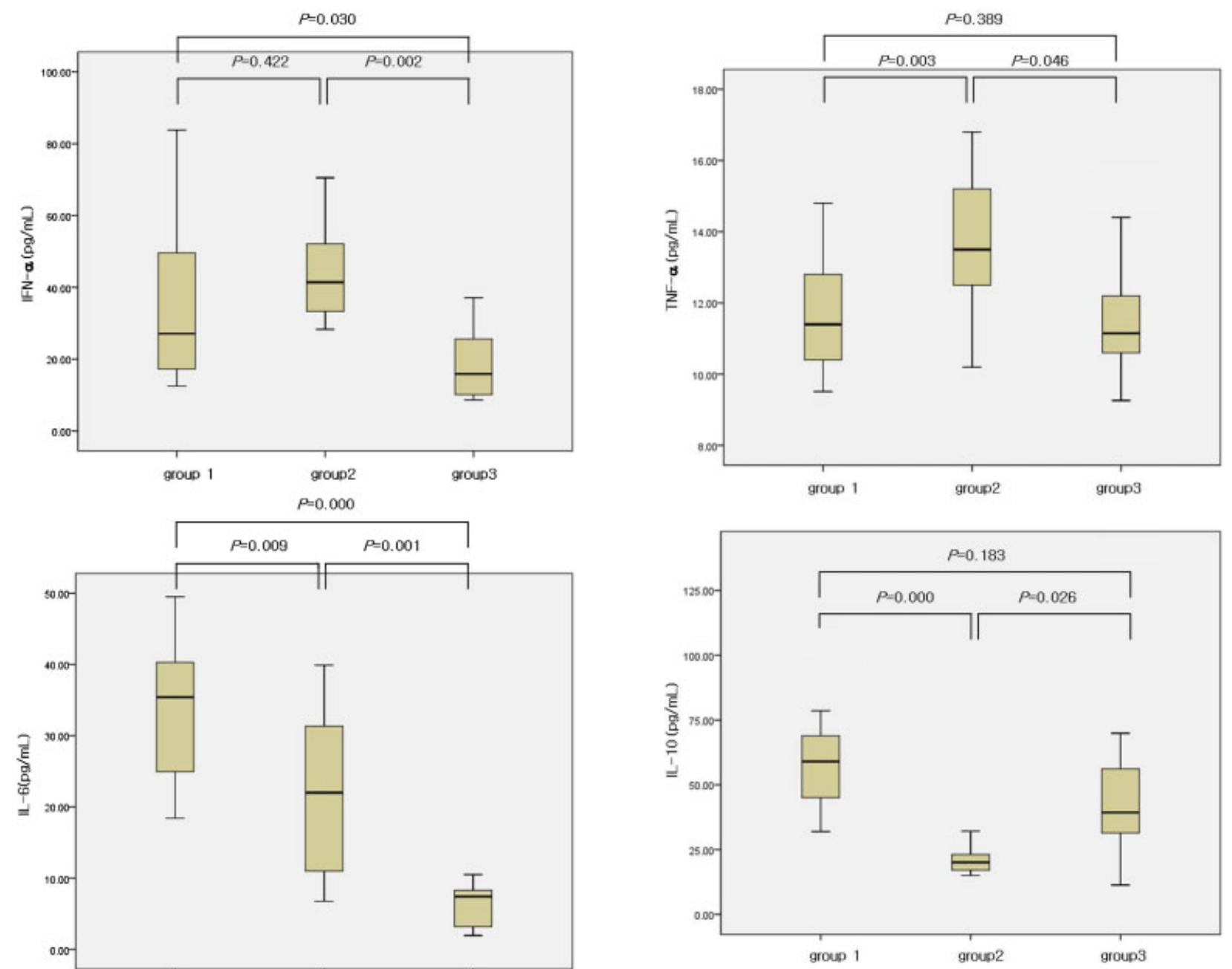

Fig. 2. Levels of cytokines (TNF- $\alpha$, IL-10) in the three groups. Median, quartiles, and range are shown. The Mann-Whitney test was used to compare cytokine levels.

group 1 and levels of IL-6 and IP-10 were negatively correlated with oxygen saturation. High cytokinemia of IL-6 and IP-10 may be derived from lung in severe H1N1 2009 cases and represent the degree of lung involvement and the severity of infection.

In the present study, IL-6 (a marker of innate immunity) levels were significantly higher in H1N1 2009 infected patients than in non-H1N1 2009 infected patients, and this was particularly true for H1N1 2009 infected patients with severe pneumonia. Our results are in accord with previous adult and pediatric studies. $5,9,10$

In the present study, we found that IP-10 (also a marker of innate immunity) levels were significantly higher in H1N1 2009 infected patients than in non-

Fig. 1. Levels of cytokines (IFN- $\alpha$, IL-6, IP-10) in the three groups. Median, quartiles, and range are shown. The MannWhitney test was used to compare cytokine levels.

H1N1 2009 infected patients. Furthermore, like IL-6, IP-10 levels were also increased, especially in those with severe pneumonia. IP-10 levels were found to be negatively correlated with lymphocyte count and 

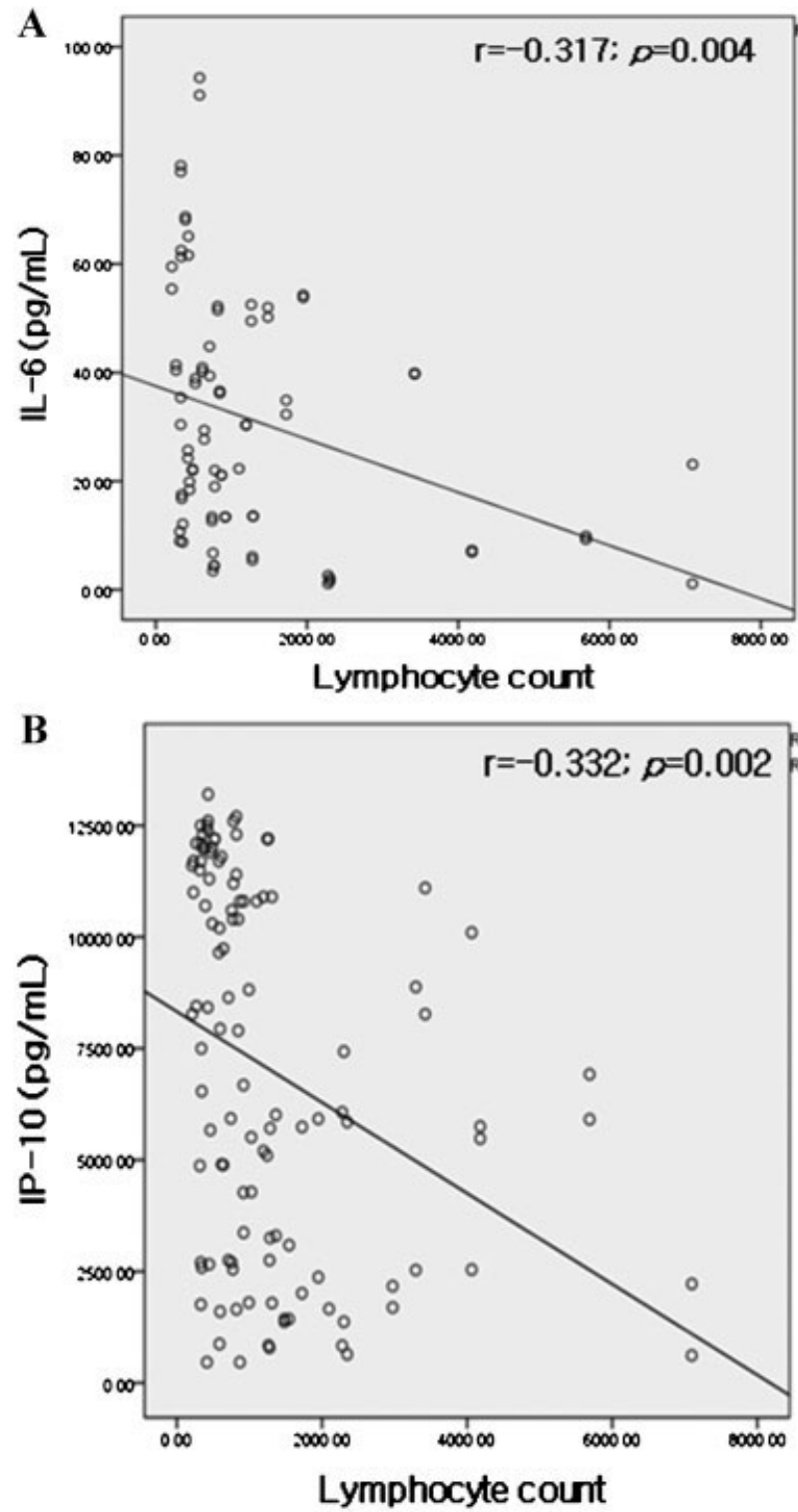

Fig. 3. Correlations (A) between IL-6 and lymphocyte count, (B) between IP-10 and lymphocyte count.

oxygen saturation in H1N1 2009 infected patients. In patients with H1N1 2009 infection, lymphocyte count and oxygen saturation were also found to be negatively correlated with disease severity (Table 1). This correlation between IP-10 levels and disease severity may be associated with its pro-inflammatory properties. In adult studies, serum IP-10 levels were found to be elevated in hospitalized H1N1 2009 infected patients, in H1N1 2009 infected patients with mild symptoms, and in critical patients with H1N1 2009 infection. ${ }^{4} 10$ Increased IP-10 levels have also been reported for other respiratory viruses, such as, in primary bronchial and tracheal epithelial cells and lung microvascular endothelial cells infected with H5N1. ${ }^{12}$ Furthermore, HRV persistence

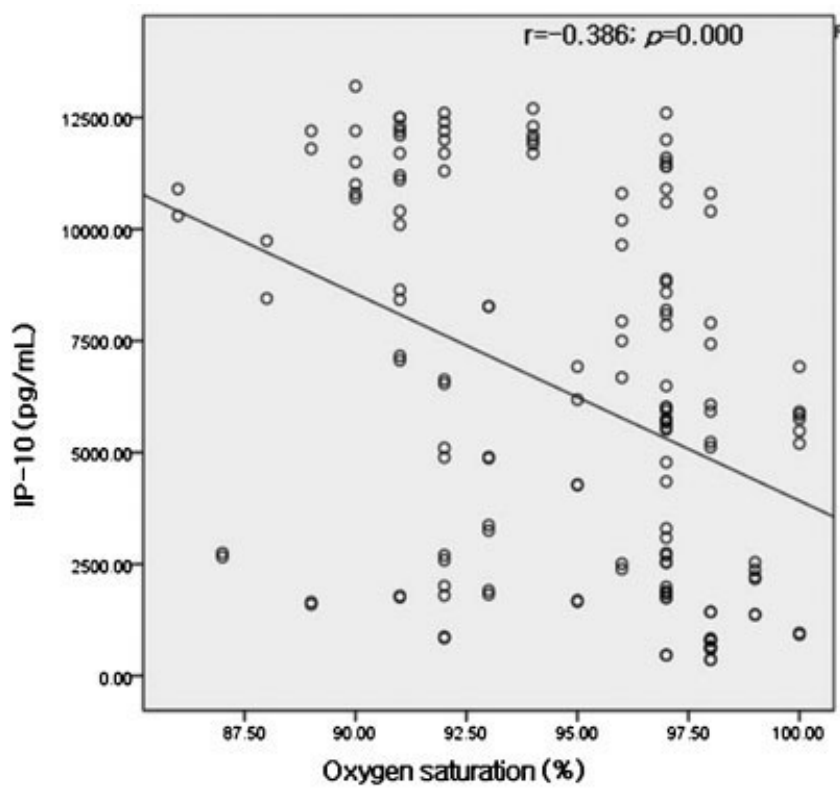

Fig. 4. Correlations between IP-10 and initial oxygen saturation in room air on the admission day.

and HRV positive asthma exacerbations have also been reported to be associated with IP-10 gene expression. $^{13,14}$

IL-10 is an anti-inflammatory cytokine with a known immunomodulatory action. In a study of H1N1 2009 infected adults, serum IL-10 was higher in critical and non-critical hospitalized patients than in outpatients with a mild infection. ${ }^{4}$ In a pediatric study, although serum IL-10 was no different in H1N1 2009 infected patients with severe pneumonia and those with mild pneumonia, IL-10 levels were significantly higher in H1N1 2009 infected patients with pneumonia than in those without pneumonia. ${ }^{5}$ Furthermore, these findings regarding IL-10 concur with our results. Because IL-10 is an anti-inflammatory cytokine with immunomodulatory properties, elevated IL-10 in severe disease may reflect additional efforts to control disease, and thus, IL-10 be might be useful for the treatment of severe disease.

IFN- $\gamma$ is a cytokine associated with innate and adaptive immunity, whereas TNF- $\alpha$ is associated with innate immunity, and both have been reported to be expressed at higher levels in patients with severe H1N1 2009 infection. ${ }^{4,5,10}$ However, in the present study, the serum levels of these cytokines were similar in the three study groups.

On the other hand, we found that the serum levels of several cytokines associated with innate immunity were significantly elevated, whereas IL-17 (associated with adaptive immunity) was expressed at similar levels in the study groups, which supports the findings of another 
pediatric study. ${ }^{5}$ We evaluated the serum level of IL-4 (a typical $\mathrm{TH} 2$ cytokine) to investigate a possible association between H1N1 2009 infection and allergic response. Twenty-two of these 57 patients showed wheezing, but IL-4 was not detected in most of these 22 patients, suggesting the lack of an association between H1N1 2009 infection and allergic response. Furthermore, other immune mediators, such as, IL-1 $\beta$ and MIP- $1 \alpha$, were also not detected in the majority of these patients.

Current opinion suggest; (1) respiratory viral infections cause lung inflammation and damage, (2) inflammation caused by pneumonia may be a more important than infections caused by virus or bacteria, and (3) antiinflammatory treatment (including corticosteroid treatment) should be considered in addition to antibiotic in some cases. ${ }^{15-17}$ Although use of corticosteroids in H1N1 2009 infected patients remains controversial, several adult studies have reported that corticosteroid was administered because pro-inflammatory cytokine levels were elevated, and that it significantly reduced inflammatory response. ${ }^{10,13,18,19}$ In addition, the use of corticosteroids showed some favorable outcome and no harmful consequences. ${ }^{16,17}$ In the present study, some patients with more severe symptoms and rapid disease progression were treated with adjuvant systemic corticosteroid. Twelve of our 75 patients (6 in group 1, 4 in group 2, and 2 in group 3 ) received corticosteroids, and all appeared to benefit and achieved a good outcome. We suggest that corticosteroid would decrease proinflammatory cytokine levels (IFN- $\alpha$, IL-6, and IP-10) in H1N1 2009 infected pediatric patients, and that this would ameliorate severe disease.

The limitations of our study are a small number of subjects and the lack of a comparison with a specific respiratory viral infection. Furthermore, healthy children were not enrolled as controls.

In conclusion, we found higher levels of cytokines (IFN- $\alpha$, IL-6, and IP-10) of innate immunity than those of acquired immunity in pediatric H1N1 2009 infection. In particular, serum IP-10 and IL-6 levels were found to be negatively correlated with disease severity. Our findings suggest that IP-10 and IL-6 are important markers in pediatric H1N1 2009 infection. We believe that a more thorough understanding of cytokine response to H1N1 2009 infection is likely to be an important aid to treatment decision making.

\section{REFERENCES}

1. Perez-Padilla R, de la Rosa-Zamboni D, Ponce de Leon S, Hernandez M, Quiñones-Falconi F, Bautista E, Ramirez-Venegas A, Rojas-Serrano J, Ormsby CE, Corrales A, et al. INER Working Group on Influenza. Pneumonia and respiratory failure from swine origin influenza $\mathrm{A}(\mathrm{H} 1 \mathrm{~N} 1)$ in Mexico. N Engl J Med 2009;361:680-689.
2. Novel Swine-Origin Influenza A (H1N1) Virus Investigation Team. Dawood FS, Jain S, Finelli L, Shaw MW, Lindstrom S, Garten RJ, Gubareva LV, Xu X, Bridges CB, et al. Emergence of a novel swine-origin influenza A (H1N1) virus in humans. N Engl J Med 2009;360:2605-2615.

3. Khan K, Arino J, Hu W, Raposo P, Sears J, Calderon F, Heidebrecht C, Macdonald M, Liauw J, Chan A, et al. Spread of a novel influenza A (H1N1) virus via global airline transportation. N Engl J Med 2009;361:212-214.

4. Bermejo-Martin JF, de Lejarazu RO, Pumarola T, Rello J, Almansa R, Ramirez P, Martin-Loeches I, Varillas D, Gallegos MC, Seron C, et al. Th1 and Th17 hypercytokinemia as early host response signature in severe pandemic influenza. Crit Care 2009; 13:R201.

5. Takano T, Tajiri H, Kashiwagi Y, Kimura S, Kawashima H. Cytokine and chemokine response in children with the 2009 pandemic influenza A (H1N1) virus infection. Eur J Clin Microbiol Infect Dis 2011;30:117-120.

6. World Health Organization (WHO). The management of acute respiratory infections in children: practical guidelines for outpatient care. 1999.

7. British Thoracic Society Standards of Care Committee. British Thoracic Society guidelines for the management of community acquired pneumonia in childhood. Thorax 2002;57 suppl 1:i1-i24.

8. Itoh Y, Shinya K, Kiso M, Watanabe T, Sakoda Y, Hatta M, Muramoto Y, Tamura D, Sakai-Tagawa Y, Noda T, et al. In vitro and in vivo characterization of new swine-origin H1N1 influenza viruses. Nature 2009;460:1021-1025.

9. To KK, Hung IF, Li IW, Lee KL, Koo CK, Yan WW, Liu R, Ho KY, Chu KH, Watt CL, et al. the Pandemic H1N1 Study Group. Delayed clearance of viral load and marked cytokine activation in severe cases of pandemic H1N1 2009 influenza virus infection. Clin Infect Dis 2010;50:850-859.

10. Hagau N, Slavcovici A, Gonganau DN, Oltean S, Dirzu DS, Brezoszki ES, Maxim M, Ciuce C, Mlesnite M, Gavrus RL, et al. Clinical aspects and cytokines response in severe H1N1 influenza A virus infection. Crit Care 2010;14:R203.

11. Nakajima N, Hata S, Sato Y, Tobiume M, Katano H, Kaneko K, Nagata N, Kataoka M, Ainai A, Hasegawa H, et al. The first autopsy case of pandemic influenza (A/H1N1pdm) virus infection in Japan: detection of a high copy number of the virus in type II alveolar epithelial cells by pathological and virological examination. Jpn J Infect Dis 2010;63:67-71.

12. Thitithanyanont A, Engering A, Uiprasertkul M, Ekchariyawat P, Wiboon-Ut S, Kraivong R, Limsalakpetch A, Kum-Arb U, Yongvanitchit K, Sa-Ard-Iam N, et al. Antiviral immune responses in $\mathrm{H} 5 \mathrm{~N} 1$-infected human lung tissue and possible mechanisms underlying the hyperproduction of interferon-inducible protein IP-10. Biochem Biophys Res Commun 2010; 398:752-758.

13. Wood LG, Powell H, Grissell TV, Davies B, Shafren DR, Whitehead BF, Hensley MJ, Gibson PG. Persistence of rhinovirus RNA and IP-10 gene expression after acute asthma. Respirology 2011;16:291-299.

14. Quint JK, Donaldson GC, Goldring JJ, Baghai-Ravary R, Hurst JR, Wedzicha JA. Serum IP-10 as a biomarker of human rhinovirus infection at exacerbation of COPD. Chest 2010;137:812822.

15. Ranó A, Agustí C, Sibila O, Torres A. Associated inflammatory response in pneumonia: role of adjunctive therapy with glucocorticoids. Curr Opin Infect Dis 2006;19:179-184.

16. Falagas ME, Vouloumanou EK, Baskouta E, Rafailidis PI, Polyzos K, Rello J. Treatment options for 2009 H1N1 influenza: evaluation of the published evidence. Int J Antimicrob Agents 2010;35:421-430. 
17. Quispe-Laime AM, Bracco JD, Barberio PA, Campagne CG, Rolfo VE, Umberger R, Meduri GU. H1N1 influenza A virusassociated acute lung injury: response to combination oseltamivir and prolonged corticosteroid treatment. Intensive Care Med 2009;36:33-41.

18. Meduri GU, Tolley EA, Chrousos GP, Stentz F. Prolonged methylprednisolone treatment suppresses systemic inflammation in patients with unresolving acute respiratory distress syndrome.

Evidence for inadequate endogenous glucocorticoid secretion and inflammation induced immune cell resistance to glucocorticoids. Am J Respir Crit Care Med 2002;165:983-991.

19. Annane D, Bellissant E, Bollaert PE, Briegel J, Confalonieri M, De Gaudio R, Keh D, Kupfer Y, Oppert M, Meduri GU. Corticosteroids in the treatment of severe sepsis and septic shock in adults: a systematic review. JAMA 2009;301:23622375 . 